\title{
Serum Adiponectin Levels and Their Association with Antiretroviral Therapy and Lipid Profile in HIV-Infected Individuals in South India
}

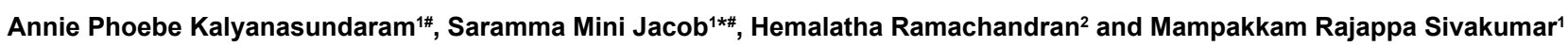

${ }^{1}$ Department of Experimental Medicine, The Tamilnadu Dr. M.G.R Medical University, Chennai, India

${ }^{2}$ Department of Oral Pathology, Ragas Dental College, Chennai, India

"These authors have contributed equally to the work

\begin{abstract}
Objective: Adiponectin is a plasma protein with anti-inflammatory and anti-atherogenic effects. Low levels of circulating adiponectin have been reported in HIV-infected patients. However, there are no studies in India on adiponectin levels in HIV-infected antiretroviral-treated and treatment-naïve subjects. Therefore, we estimated adiponectin levels in HIV-positive individuals and investigated their associations with antiretroviral therapy (ART) and lipid profile.
\end{abstract}

Materials and methods: Consenting HIV-infected and non-infected men and women were recruited from Namakkal district, Tamilnadu, India. A semi structured questionnaire was administered in the local language (Tamil) to all patients which included socio-demographics, and details on ART. Fasting blood samples were collected and anthropometric measurements obtained. Serum adiponectin levels and lipid profile levels were determined.

Results: Adiponectin levels were measured in 139 individuals of whom sixty four individuals were on ART, 36 were ART naïve, and 39 were HIV-negative subjects. HIV-infected patients had significantly lower adiponectin levels than the HIV-uninfected $(p=0.000)$. HIV-positive patients had a 17.92-fold decrease in adiponectin values when compared to HIV-negative controls. Also, patients on ART had a 21-fold decrease in adiponectin levels when compared to ARTnaïve patients. Moreover, patient's currently or previously receiving stavudine treatment had a 3.8-fold decrease in adiponectin levels when compared to those who had never received stavudine. Regarding lipid profile, high density lipoprotein (HDL) - cholesterol was positively associated with adiponectin $(p=0.004)$ while very low density lipoprotein (VLDL) - cholesterol $(p=0.017)$ and triglycerides $(p=0.017)$ showed a negative association in patients on ART. Adiponectin concentration in patients on ART with dyslipidemia was significantly decreased as compared to those without dyslipidemia $(p=0.030)$.

Conclusion: Serum adiponectin levels were lower in this HIV-infected South Indian population as compared to HIVnegative controls. Stavudine seemed to influence adiponectin levels. The significant association between ART-induced hypoadiponectinemia and adverse changes in lipid profile suggests a higher risk of atherosclerosis in this population.

Keywords: Human immunodeficiency virus; Adiponectin; Antiretroviral therapy; Lipid profile; Dyslipidemia; Namakkal; South India

\section{Introduction}

The National AIDS Control Organization (NACO, Government of India) set up antiretroviral therapy (ART) centers in Government hospitals throughout the country since 2004. As of March 2014, 768,840 individuals are on ART, which was provided free from the Government [1]. Most of these patients are on triple drug regimen containing two nucleoside reverse transcriptase inhibitors (NRTIs) and one non-nucleoside reverse transcriptase inhibitor (NNRTI). These combination therapies have improved the prognosis of patients by viral suppression, enhanced the quality of life and increase their life spans. However, long-term major complications like lipodystrophy, which is a disorder of adipose tissue distribution, and dyslipidemia, have been reported in these patients [2].

The adipose tissue is an important metabolic organ which secretes numerous factors such as adiponectin, leptin, resistin, acylationstimulating protein and visfatin [3]. Adiponectin is a plasma protein which has inverse associations with hypertension, inflammation, insulin resistance, type 2 diabetes and dyslipidemia [4,5]. Adiponectin is associated with favourable lipid profile, having positive correlations with high density lipoprotein (HDL)-cholesterol and negative correlations with low density lipoprotein (LDL)-cholesterol, very low density lipoprotein (VLDL)-cholesterol and triglycerides [5].

Low levels of circulating adiponectin have been reported in HIV- infected patients [7]. Adiponectin levels are significantly reduced in treated and untreated HIV patients and may have a direct effect on lipoprotein metabolism, which may be independent of insulin [8].There is an increase of total cholesterol and LDL-cholesterol in correlation with the decrease of adiponectin concentration in HIV-infected patients [9]. Also, lower adiponectin levels in HIV-infected men are associated with subclinical atherosclerosis, independent of traditional cardiovascular disease risk factors [10]. Moreover, combination ART lasting longer than 2 years result in the decrease of adiponectin concentration [9]. However, a recent study reported that the hypoadiponectinemia exhibited by H1V-1 infected patients is not influenced by ART use [11].

There are no studies in India on adiponectin levels in HIV-infected antiretroviral-treated and treatment-naïve subjects. The purpose of our study was to estimate adiponectin levels in HIV-infected men and

*Corresponding author: Saramma Mini Jacob, Department of Experimental Medicine, The Tamilnadu Dr. M.G.R Medical University, Anna Salai, Guindy, Chennai-600032, India, Tel: +91 44 22300779; E-mail: saramini@yahoo.com

Received May 27, 2014; Accepted September 25, 2015; Published September 30, 2015

Citation: Kalyanasundaram AP, Jacob SM, Ramachandran $H$, Sivakumar MR (2015) Serum Adiponectin Levels and Their Association with Antiretroviral Therapy and Lipid Profile in HIV-Infected Individuals in South India. J AIDS Clin Res 6: 504. doi:10.4172/2155-6113.1000504

Copyright: (C) 2015 Kalyanasundaram AP, et al. This is an open-access article distributed under the terms of the Creative Commons Attribution License, which permits unrestricted use, distribution, and reproduction in any medium, provided the original author and source are credited. 
women in South India and compare them to uninfected individuals. Further we studied whether antiretroviral therapy was associated with low adiponectin levels in this population. In addition we investigated the association of adiponectin with lipid profile and dyslipidemia.

\section{Materials and Methods}

\section{Study participants}

In this cross-sectional study, initially 297 subjects (225 HIV-infected and 72 uninfected subjects) were enrolled from April 2006 to May 2009. Seventy-nine HIV-infected patients on ART, visiting the ART center at Namakkal District Head Quarters Hospital, Tamil Nadu, India, were recruited. They were on generic first-line fixed dose combinations of ART, provided for free by the Indian Government under its national ART program. One hundred and forty-six ART=naïve HIV positive individuals visiting the ART center for ART screening, and follow-up clinics at the Prevention of Mother to Child Transmission (PMTCT) centers in Namakkal District, and 72 healthy HIV negative adults who had accompanied the HIV positive patients were also recruited. All the subjects were aged 18 to 45 years. The exclusion criteria for all the subjects were active substance abuse, regular alcohol consumption, current usage of anabolic steroids, glucocorticoids, lipid-lowering or hypoglycemic drugs, recent opportunistic infection or malignancy.

Due to the limited availability of adiponectin ELISA kits, adiponectin levels were determined for 139 subjects who were selected randomly from the total 297 subjects. The study was conducted by the Department of Experimental Medicine, The TN Dr.MGR Medical University, Chennai, after obtaining approval from the University's Ethics Committee. Written informed consent was obtained from all the subjects prior to enrollment.

\section{Assessments and measurements}

A semi-structured questionnaire was administered in the local language (Tamil), which was spoken by all patients. The questionnaire was explained in detail to the patients to ensure all subjects understood the requirements Sociodemographic information, anthropometric measurements, and details of type and duration of ART regimen were recorded. Anthropometric measurements included body weight $(\mathrm{kg})$, height $(\mathrm{cm})$, waist circumference $(\mathrm{cm})$ and hip circumference $(\mathrm{cm})$. Body Mass Index (BMI, weight in $\mathrm{kg}$ divided by the square of the height in $\mathrm{m}$ ) was calculated.

An overnight fasting blood was drawn and aliquots of serum were stored at $-80^{\circ} \mathrm{C}$ until analysis. Total cholesterol, high-density lipoprotein
(HDL) cholesterol, and triglycerides were analyzed by colorimetric enzymatic methods with reagents purchased from Identii (Spain) using Stat Fax 3300 chemistry analyzer (Awareness Technology, USA). Lowdensity lipoprotein (LDL) cholesterol and Very-density lipoprotein (VLDL) was calculated using the Friedewald formula. CD4 ${ }^{+} \mathrm{T}$ Cell Counts were determined by Flow Cytometry (FACScan Analyzer, Becton Dickinson, USA). Adiponectin levels were determined by human adiponectin enzyme-linked immunosorbent assay (ELISA) kits (Ray Biotech, USA) using Biorad ELISA Reader, USA. The minimum detection limit for adiponectin assay was $25 \mathrm{pg} / \mathrm{ml}$. The inter-assay coefficient of variation was $5.92 \%$.

Low adiponectin level was defined was $<4 \mu \mathrm{g} / \mathrm{ml}$ [12]. Dyslipidemia was defined as any one of the following: total cholesterol (total-C) $\geq 200$ $\mathrm{mg} / \mathrm{dL}$, high-density lipoprotein cholesterol (HDL-C) $\leq 40 \mathrm{mg} / \mathrm{dL}$, lowdensity lipoprotein cholesterol (LDL-C) $\geq 130 \mathrm{mg} / \mathrm{dL}$, and triglycerides (TG) $\geq 150 \mathrm{mg} / \mathrm{dL}$ by the US National Cholesterol Education Program (NCEP) III guidelines[13].

\section{Statistical analysis}

Data was collected on an individual case basis and then translated to the SPSS statistics software Version 11.0.1. Means, standard deviations, and percentages of various variables were calculated. For non-normal data, medians and interquartile ranges (IQR: 25\%, 75\%) were presented. Proportions between characteristics of the study groups were compared by chi-square test. Mann-Whitney $U$ test was utilized to compare the anthropometric measurements, biochemical and immunological values between HIV- infected and uninfected subjects. Correlations of adiponectin levels with lipid profile were presented. Both univariate and multivariate regression analysis was done for adiponectin levels with respect to the study characteristics. Model validity was checked by $\mathrm{R}^{2}$ statistic, diagnostic of the residual by checking mean square error, Durbin-Watson statistic and scatter plots of residuals versus predictors. A P value of $\leq 0.05$ was considered as statistically significant.

\section{Results}

Among the 139 subjects with adiponectin measurements $(44.6 \%$ men, $55.4 \%$ women), 100 were HIV-positive subjects ( 64 were on ART, 36 were antiretroviral-naive,) and 39 were HIV- negative subjects. Among the patients on ART, 53.1\% were on AZT (zidovudine)/3TC (lamivudine)/NVP (Nevirapine), $45.3 \%$ on $\mathrm{d} 4 \mathrm{~T}$ (stavudine)/3TC/ NVP and $1.6 \%$ were on $\mathrm{d} 4 \mathrm{~T} / 3 \mathrm{TC} / \mathrm{EFV}$ (efavirenz). Demographic, anthropometric and lipid profile characteristics of the study subjects are shown in Table 1.

\begin{tabular}{|c|c|c|c|}
\hline Parameters & HIV-infected patients on ART $(n=64)$ & HIV-infected ART-naïve patients ( $n=36)$ & HIV-negative $(n=39)$ \\
\hline $\begin{array}{l}\text { Male, } \mathrm{n}(\%) \\
\text { Female, } \mathrm{n}(\%)\end{array}$ & $\begin{array}{l}30(46.9) \\
34(53.1)\end{array}$ & $\begin{array}{l}14(38.9) \\
22(61.1)\end{array}$ & $\begin{array}{l}18(46.2) \\
21(53.8)\end{array}$ \\
\hline Age $(y r s) * \ddagger$ & $36.00(30.25-40.00)$ & $30.00(26.25-34.00)$ & $33.00(30.00-41.00)$ \\
\hline Duration of therapy (months) & $29.00(19.00-40.00)$ & --------- & --------- \\
\hline $\mathrm{BMI}\left(\mathrm{kg} / \mathrm{m}^{2}\right)^{* \dagger \ddagger}$ & $22.15(19.45-25.72)$ & $19.32(17.75-21.93)$ & $26.20(21.80-29.60)$ \\
\hline $\mathrm{WHR}^{*} \neq$ & $0.89(0.84-0.94)$ & $0.83(0.79-0.88)$ & $0.91(0.86-0.94)$ \\
\hline CD4 count $(/ \mu \mathrm{l})$ & $530.50(330.75-627.75)$ & $335.50(117.23-163.48)$ & -------- \\
\hline Total Cholesterol $(\mathrm{mg} / \mathrm{dl}) * \ddagger$ & $170.1(146.83-200.65)$ & $133.8(117.23-163.48)$ & $166.50(148.30-198.00)$ \\
\hline $\mathrm{HDL}-\mathrm{C}(\mathrm{mg} / \mathrm{dl})$ * † & $54.35(45.48-65.23)$ & $34.65(29.75-42.68)$ & $44.90(37.70-54.60)$ \\
\hline LDL-C (mg/dl) & $79.32(61.57-109.91)$ & $80.31(73.37-96.18)$ & $97.00(81.6-117.00)$ \\
\hline VLDL-C $(\mathrm{mg} / \mathrm{dl})$ * & $23.18(17.34-40.09)$ & $13.32(10.04-19.55)$ & $22.68(13.10-36.60)$ \\
\hline Triglycerides $(\mathrm{mg} / \mathrm{dl})$ * & $115.90(86.68-200.43)$ & $82.60(55.27-113.90)$ & $113.4(65.50-183.30)$ \\
\hline
\end{tabular}

Median values with Inter Quartile Range (IQR) are given. *Significant difference among patients on ART and ART-naïve; †Significant difference among patients on ART and HIV-negative; ₹ Significant difference among patients on ART-naïve and HIV-negative.

Table 1: Characteristics of study subjects. 


\section{Adiponectin levels}

The median adiponectin level among the study population was $11.77(\mathrm{IQR}=2.17-22.6) \mu \mathrm{g} / \mathrm{ml}$. Median adiponectin levels did not differ significantly with gender $(\mathrm{p}=0.348)$ in both the HIV-positive and HIVnegative groups in this study population (Table 2). Also, adiponectin was not associated significantly with CD4 counts among the HIVinfected patients (data not shown).

\section{Adiponectin and HIV-serostatus}

The proportion of subjects with low adiponectin level $(<4 \mu \mathrm{g} / \mathrm{ml})$ was significantly higher among the HIV-infected as compared to uninfected controls ( $97.6 \%$ vs. $2.4 \%$; $\mathrm{p}=0.00)$. Moreover, HIV-infected patients had significantly lower median adiponectin levels than the HIV-uninfected (Table 2). The difference in adiponectin levels by HIV-serostatus remained significant after adjusting for age, sex and BMI by multivariate regression analysis which was performed with adiponectin concentration as dependent variable and BMI, age, sex and HIV-serostatus as independent variables (Table 3). HIV-positive patients had a 17.92-fold decrease in adiponectin values when compared to HIV-negative controls. By partial correlation, HIV-seropositivity was significantly associated with decreased adiponectin levels after controlling for BMI $(r=-0.363, p=0.00)$.

\section{Adiponectin and antiretroviral therapy}

There was a significantly higher proportion of patients on ART with a low adiponectin level as compared to ART-naive patients and HIVnegative individuals (ART $=88.1 \%$, ART-naïve $=9.5 \%, \mathrm{HIV}$-ve $=2.4 \%$; $\mathrm{p}=0.00$ ). Also, patients on ART had significantly lower median levels of adiponectin when compared to ART-naive and HIV-negative individuals [ART $=2.51 \quad(\mathrm{IQR}=0.34-9.15) \quad \mu \mathrm{g} / \mathrm{ml}, \quad$ ART-naïve $=18.49$ $(\mathrm{IQR}=10.02-33.05) \mu \mathrm{g} / \mathrm{ml}, \mathrm{HIV}$-ve $=22.6(\mathrm{IQR}=14.43-38.22) \mu \mathrm{g} / \mathrm{ml}$; $\mathrm{p}=0.00$.]. Multivariate regression analysis showed that patients on ART had a 21-fold decrease in adiponectin levels when compared to ARTnaïve patients after controlling for age, sex and BMI (Table 4).

\begin{tabular}{|l|c|c|c|}
\hline Gender & HIV-positive & HIV-negative & P-value \\
\hline Male & $5.19(0.57-15.91)$ & $20.91(10.77-37.81)$ & 0.000 \\
\hline Female & $6.03(0.61-18.13)$ & $22.6(15.45-41.63)$ & 0.000 \\
\hline Total & $5.90(0.59-16.83)$ & $22.6(14.43-38.22)$ & 0.000 \\
\hline
\end{tabular}

Median values with inter quartile range (IQR) are given.

Table 2: Adiponectin levels $(\mu \mathrm{g} / \mathrm{ml})$.

\begin{tabular}{|l|c|c|c|}
\hline Variables & $\boldsymbol{\beta}$ & $\mathbf{9 5 \%} \mathbf{C l}$ & P-value \\
\hline Age & -0.319 & $-0.916-0.277$ & 0.292 \\
\hline Sex & 1.308 & $-5.989-8.605$ & 0.724 \\
\hline BMI & -0.853 & $-1.668--0.038$ & 0.040 \\
\hline HIV-serostatus & -17.921 & $-25.942--9.900$ & 0.000 \\
\hline
\end{tabular}

$\beta=$ Regression Coefficient. HIV serostatus was coded as 0 for HIV-negative and 1 for HIV-positive patients.

Table 3: Multivariate regression for the association of adiponectin with age, sex, $\mathrm{BMI}$ and HIV-serostatus.

\begin{tabular}{|l|c|c|c|}
\hline Variables & $\boldsymbol{\beta}$ & $\mathbf{9 5 \%} \mathbf{C l}$ & P-value \\
\hline Age & 0.127 & $-0.579-0.834$ & 0.721 \\
\hline Sex & 1.156 & $-6.979-9.292$ & 0.778 \\
\hline BMI & -0.902 & $-1.955-0.150$ & 0.092 \\
\hline ART & -21.004 & $-29.145--12.862$ & 0.000 \\
\hline
\end{tabular}

$\beta=$ Regression Coefficient. ART was coded as 0 for ART-naïve and 1 for patients on ART.

Table 4: Multivariate regression for the association of adiponectin with age, sex, $\mathrm{BMI}$ and $\mathrm{ART}$.
Among the patients on ART, 34 (53.1\%) were presently on zidovudine regimen and $30(46.9 \%)$ were presently on stavudine regimen. Patients presently on stavudine based treatment had moderately lower adiponectin levels than Zidovudine based regimens. $[1.7(\mathrm{IQR}=0.22-7.67) \mu \mathrm{g} / \mathrm{ml}$ vs. $4.38(\mathrm{IQR}=0.35-11.70) \mu \mathrm{g} / \mathrm{ml}, \mathrm{p}=0.218]$. Adiponectin levels were significantly lower among patients currently or previously receiving stavudine regimens $(n=48)$ as compared to those who had never received stavudine $(\mathrm{n}=16)$ [1.48 $(\mathrm{IQR}=0.22-6.1) \mu \mathrm{g} /$ $\mathrm{ml}$ vs. 6.35 ( $\mathrm{IQR}=1.1-14.11) \mu \mathrm{g} / \mathrm{ml}, \mathrm{p}=0.01]$. Multivariate regression analysis showed that patients currently or previously receiving stavudine treatment had a 3.8-fold decrease in adiponectin levels when compared to those who had never received stavudine, after controlling for age, sex and BMI ( $\beta=-3.846,95 \% \mathrm{CI}=-7.286--0.405, \mathrm{p}=0.029)$.

Adiponectin levels did not show significant variation with duration of therapy.

\section{Adiponectin and lipid profile values}

Correlation analysis was performed between lipid profile and adiponectin levels of HIV-infected and uninfected subjects. The results showed a significant negative correlation of lipid profile values with serum adiponectin levels in the HIV-positive group. The $r$ values and their corresponding $\mathrm{p}$ values were $-0.354(\mathrm{p}=0.00)$ for total-Cholesterol, $-0.222(p=0.027)$ for HDL-Cholesterol, $-0.479(p=0.00)$ for VLDLCholesterol, and $-0.403(\mathrm{p}=0.00)$ for triglycerides. LDL-cholesterol did not show any association with adiponectin $(\mathrm{r}=-0.055, \mathrm{p}=0.635)$. There were no correlations between adiponectin and lipid profile among HIVnegative subjects.

When correlation analysis was performed separately for patients on ART, and ART-naïve patients, significant correlations were seen only for patients on ART (Table 5). HDL-cholesterol showed a significant positive correlation in this group while VLDL-cholesterol and triglycerides showed a significant negative association with adiponectin. However, total cholesterol did not show any association with adiponectin.

All of the associations remained statistically significant after controlling for age and sex in the ART group (Table 6). When further analyses were performed in the ART group controlling for age, sex and BMI, HDL-Cholesterol continued to show a significant positive association with adiponectin (regression coefficient $\beta=0.145,95 \% \mathrm{CI}=$ 0.049-0.241, $\mathrm{p}=0.004)$ while VLDL-cholesterol $(\beta=-0.080,95 \% \mathrm{CI}=$ $-0.146--0.015, \mathrm{p}=0.017)$ and triglycerides $(\beta=-0.016,95 \% \mathrm{CI}=-0.029$ $-0.003, \mathrm{p}=0.017)$ showed a negative association.

\section{Adiponectin and dyslipidemia}

Among the HIV-infected on ART, adiponectin concentration in subjects with dyslipidemia was significantly decreased as compared to those without dyslipidemia [3.67 (IQR=0.22-5.78) $\mu \mathrm{g} / \mathrm{ml}$ vs. 6.76 $(\mathrm{IQR}=0.67-11.77) \mu \mathrm{g} / \mathrm{ml}, \mathrm{p}=0.035]$. The significance remained after adjusting for age, sex and BMI $(\beta=-1.427,95 \% \mathrm{CI}=-2.709--0.144$, $\mathrm{p}=0.030$ ). On analyses of individual lipid profile levels, adiponectin concentration was significantly decreased with elevated triglyceride levels and moderately decreased with low HDL-cholesterol levels (Table 7). There were no significant changes in adiponectin concentration in ART-naïve and HIV-negative subjects with dyslipidemia.

\section{Discussion}

In this study of adiponectin levels in a rural South Indian population, there were several noteworthy findings. We observed that low adiponectin levels were significantly more prevalent among HIV- 


\begin{tabular}{|c|c|c|c|c|c|c|}
\hline \multirow[t]{2}{*}{$\square$} & \multicolumn{2}{|c|}{ HIV-infected patients on ART $(n=64)$} & \multicolumn{2}{|c|}{ HIV-infected ART-naïve patients $(n=36)$} & \multicolumn{2}{|c|}{ HIV-negative $(n=39)$} \\
\hline & $\mathbf{r}$ & P-value & $\mathbf{r}$ & P-value & $\mathbf{r}$ & P-value \\
\hline Total Cholesterol (mg/dl) & -0.184 & 0.147 & -0.116 & 0.500 & -0.015 & 0.928 \\
\hline HDL-Cholesterol (mg/dl) & 0.371 & 0.003 & 0.069 & 0.688 & -0.137 & 0.407 \\
\hline LDL-Cholesterol (mg/dl) & -0.148 & 0.243 & 0.282 & 0.329 & 0.178 & 0.278 \\
\hline VLDL-Cholesterol (mg/dl) & -0.359 & 0.004 & -0.080 & 0.787 & -0.216 & 0.187 \\
\hline Triglycerides (mg/dl) & -0.359 & 0.004 & -0.032 & 0.853 & -0.216 & 0.187 \\
\hline
\end{tabular}

$r=$ Correlation Coefficient.

Table 5: Correlation of adiponectin levels with lipid profile.

\begin{tabular}{|c|c|c|c|c|c|c|c|c|c|}
\hline \multirow[t]{2}{*}{$\square$} & \multicolumn{3}{|c|}{ HIV-infected patients on ART $(n=64)$} & \multicolumn{3}{|c|}{ HIV-infected ART-naive patients ( $n=36$ ) } & \multicolumn{3}{|c|}{ HIV-negative ( $n=39$ ) } \\
\hline & $\beta$ & $95 \% \mathrm{Cl}$ & P-value & $\beta$ & $95 \% \mathrm{Cl}$ & P-value & $\beta$ & $95 \% \mathrm{Cl}$ & P-value \\
\hline Total Cholesterol (mg/dl) & -0.018 & $-0.043-0.006$ & 0.138 & -0.093 & $-0.461-0.275$ & 0.609 & 0.028 & $-0.169-0.226$ & 0.774 \\
\hline HDL-Cholesterol (mg/dl) & 0.157 & $0.056-0.257$ & 0.003 & 0.180 & $-0.725-1.086$ & 0.688 & -0.134 & $-0.530-0.262$ & 0.497 \\
\hline LDL-Cholesterol (mg/dl) & -0.016 & $-0.042-0.010$ & 0.228 & 0.390 & $-0.376-1.157$ & 0.283 & 0.111 & $-0.093-0.315$ & 0.277 \\
\hline VLDL-Cholesterol (mg/dl) & -0.099 & $-0.164-0.033$ & 0.004 & -0.386 & $-2.682-1.910$ & 0.716 & -0.188 & $-0.608-0.232$ & 0.370 \\
\hline Triglycerides (mg/dl) & -0.020 & $-0.033--0.007$ & 0.004 & -0.012 & $-0.262-0.237$ & 0.920 & -0.038 & $-0.122-0.046$ & 0.369 \\
\hline
\end{tabular}

$\beta=$ Regression Coefficient.

Table 6: Regression coefficients for the association of adiponectin with lipid profile after adjusting for age and sex.

\begin{tabular}{|c|c|c|}
\hline Lipid Parameters & Adiponectin & $P$ value \\
\hline $\begin{array}{l}\text { Total Cholesterol }<200 \mathrm{mg} / \mathrm{dL} \\
\text { Total Cholesterol } \geq 200 \mathrm{mg} / \mathrm{dL}\end{array}$ & $\begin{array}{l}2.83(0.40-9.15) \\
0.64(0.16-9.30)\end{array}$ & 0.185 \\
\hline $\begin{array}{l}\mathrm{HDL}-\text { Cholesterol }>40 \mathrm{mg} / \mathrm{dL} \\
\mathrm{HDL}-\text { Cholesterol } \leq 40 \mathrm{mg} / \mathrm{dL}\end{array}$ & $\begin{array}{l}3.05(0.35-9.61) \\
0.22(0.08-7.61)\end{array}$ & 0.099 \\
\hline $\begin{array}{l}\text { LDL-Cholesterol }<130 \mathrm{mg} / \mathrm{dL} \\
\text { LDL-Cholesterol } \geq 130 \mathrm{mg} / \mathrm{dL}\end{array}$ & $\begin{array}{c}2.41(0.34-10.02) \\
3.81(0.22-5.90)\end{array}$ & 0.805 \\
\hline $\begin{array}{l}\text { VLDL-Cholesterol }<500 \mathrm{mg} / \mathrm{dL} \\
\text { VLDL-Cholesterol } \geq 500 \mathrm{mg} / \mathrm{dL}\end{array}$ & 2.51 (0.34-9.15) & ------- \\
\hline $\begin{array}{l}\text { Triglycerides }<150 \mathrm{mg} / \mathrm{dL} \\
\text { Triglycerides } \geq 150 \mathrm{mg} / \mathrm{dL}\end{array}$ & $\begin{array}{c}5.90(0.70-11.91) \\
0.42(0.22-3.17)\end{array}$ & 0.001 \\
\hline
\end{tabular}

Median values with Inter Quartile Range (IQR) are given.

Table 7: Adiponectin concentrations in NCEP III normal and elevated lipid parameters among HIV-infected subjects on ART.

infected patients as compared to uninfected controls. We also observed that lower adiponectin levels were associated with ART, particularly stavudine treatment. We demonstrated that adiponectin levels were positively correlated with HDL-cholesterol and negatively correlated with triglycerides and VLDL-cholesterol in HIV-infected patients on ART. We also found that adiponectin concentration decreased in antiretroviral-treated patients with dsylipidemia, particularly hypertriglyceridemia. To our knowledge, this is the first study in India to examine adiponectin levels in HIV-infected patients as compared to uninfected individuals and identify their associations with ART and serum lipid levels.

Adiponectin has anti-atherogenic and anti-inflammatory properties [14] and protects against obesity-related cardiovascular and metabolic diseases [4]. Adiponectin affects the lipid catabolism [15] and $\beta$-oxidation of lipids and triglyceride clearance [16]. Reduced adiponectin levels are associated with obesity [17] and type 2 diabetes [18-20]. In the general population, hypoadiponectinemia has been associated with an increased risk of cardiovascular disease [21,22].

Adiponectin levels were lower in HIV infected individuals as compared to uninfected individuals, with as much as $97.6 \%$ of the HIV-infected patients having a low adiponectin level. Low levels of adiponectin have been reported in other HIV-infected populations $[7,10,23]$. While one study demonstrated that lower adiponectin levels were related to the severity of subclinical atherosclerosis, independent of traditional cardiovascular disease risk factors [10], another study reported that coronary artery disease was marginally associated with low adiponectin levels in HIV-infected men [23], suggesting that low adiponectin levels may play a role in the pathogenesis of cardiovascular disease among HIV-infected persons.

Successful combination antiretroviral therapy (cART) with the goal to suppress viral replication and to improve quality of life with immune restoration has significantly altered the prognosis of HIV patients in India. However, long term complications of treatment have become an important concern to the patient and their treating clinician. Our data shows reduced adiponectin levels in patients on ART and this data is consistent with other studies from France [24] and the United Kingdom [25]. Hypoadiponectinemia in patients on ART has been observed to be associated with accelerated cardiovascular impairment [26]. Dysfunctional adipose tissue in HIV-infected patients under ART leading to suppression of adiponectin levels may deteriorate numerous metabolic parameters leading to detrimental cardiovascular events [27]. In our study, patients on stavudine-based treatment had significantly lower adiponectin levels than those on Zidovudinebased regimens. Similar observations were noted in patients on stavudine line of treatment in Denmark [28] and the United States [29] with the suggestion that stavudine alters adipocyte function and reduces adiponectin secretion from adipocytes.

Our study demonstrated the relationship between adiponectin and lipid profile and argues in favor of an important physiologic role of adiponectin in lipid metabolism. HDL-cholesterol showed a significant positive correlation while VLDL-cholesterol and triglycerides showed a significant negative association with adiponectin, independent 
Citation: Kalyanasundaram AP, Jacob SM, Ramachandran H, Sivakumar MR (2015) Serum Adiponectin Levels and Their Association with Antiretroviral Therapy and Lipid Profile in HIV-Infected Individuals in South India. J AIDS Clin Res 6: 504. doi:10.4172/2155-6113.1000504

Page 5 of 6

of BMI, in patients on ART. Similar findings have been reported in other studies. For example, a study from the United States observed that adiponectin inversely correlated with triglycerides and positively with HDL-cholesterol in HIV-infected patients [30]. Another study from China reported that adiponectin correlated with triglycerides and HDL-cholesterol in HIV-infected lipodsytrophic patients [31]. The regulatory effect of adiponectin on hepatic lipase activity may help explain the HDL-cholesterol elevating action of adiponectin [32]. Also, adiponectin may decrease plasma triglyceride levels by increasing skeletal muscle lipoprotein lipase and VLDL receptor expression and consequently VLDL-triglyceride catabolism [33].

Moreover, we observed a significant decrease in adiponectin concentration in dyslipidemia, particularly elevated triglycerides level, with a moderate decrease in low levels of HDL-cholesterol. There are several studies regarding hypoadiponectinemia in dyslipidemia in the general population $[34,35]$. There are also studies demonstrating significant correlations between adiponectin concentration and dyslipidemia, particularly hypertriglyceridemia in the HIVinfected population [36-38]. However, this is the first study in India to demonstrate such an association. Since adiponectin has antiatherogenic properties, hypoadiponectinemia in dyslipidemia may accelerate the atherogenic reaction [34].

Limitations of our study include the cross-sectional study design. Better estimates of changes in adiponectin levels associated with antiretroviral agents can be obtained from clinical trials and longitudinal observational studies of individuals before and after initiation of therapy. Another limitation of the study was the sample size. We were not able to assess adiponectin levels for our entire study samples $(n=297)$ due to the cost of the Adiponectin ELISA kits and their availability.

\section{Conclusions}

Adiponectin levels were lower in HIV infected individuals, in this South Indian population. ART, particularly stavudine, seemed to influence adiponectin levels in the HIV-infected group. Adiponectin had a significant positive association with HDL-cholesterol and negative association with VLDL-cholesterol and triglycerides in HIV-infected patients on ART. The significant association between ART-induced hypoadiponectinemia and adverse changes in lipid profile suggests a higher risk of atherosclerosis in this population.

\section{Acknowledgements}

We thank Mr. G Thatchinamoorthy and Mr. A Ganesan for their assistance in performing laboratory assays. We would like to thank all the patients who took part in the study.

\section{Funding}

The authors received no funding from external sources.

\section{References}

1. NACO 2014. Journey of ART Programme in India.

2. Kalyanasundaram AP, Jacob SM, Hemalatha R, Sivakumar MR (2012) Prevalence of lipodystrophy and dyslipidemia among patients with HIV infection on generic ART in rural South India. J Int Assoc Physicians AIDS Care (Chic) 11: 329-334.

3. Scherer PE (2006) Adipose tissue: From lipid storage compartment to endocrine organ. Diabetes 55: 1537-1545.

4. Okamoto Y, Kihara S, Funahashi T, Matsuzawa Y, Libby P (2006) Adiponectin: A key adipocytokine in metabolic syndrome. Clin Sci (Lond) 110: 267-278.

5. Mantzoros CS, Li T, Manson JE, Meigs JB, Hu FB (2005) Circulating adiponectin levels are associated with better glycemic control, more favorable lipid profile, and reduced inflammation in women with type 2 diabetes. $\mathrm{J}$ Clin Endocrinol Metab 90: 4542-4548.

6. Izadi V, Farabad E, Azadbakht L (2013) Epidemiologic evidence on serum adiponectin level and lipid profile. Int J Prev Med 4: 133-140.

7. Mynarcik DC, Combs T, McNurlan MA, Scherer PE, Komaroff E, et al. (2002) Adiponectin and leptin levels in HIV-infected subjects with insulin resistance and body fat redistribution. J Acquir Immune Defic Syndr 31: 514-520.

8. Das S, Shahmanesh M, Stolinski M, Shojaee-Moradie F, Jefferson W, et al (2006) In treatment-naïve and antiretroviral-treated subjects with HIV, reduced plasma adiponectin is associated with a reduced fractional clearance rate of VLDL, IDL and LDL apoliprotein B-100. Diabetologia 49: 538-542.

9. Leszczyszyn-Pynka M, Pynka S, Boron-Kaczmarska A, Pilarska K (2005) Serum leptin and adiponectin concentrations in patients infected with human immunodeficiency virus type 1 (HIV-1) on antiretroviral therapy. Endokrynol Pol 56: 19-24.

10. Ketlogetswe KS, Post WS, Li X, Palella FJ Jr, Jacobson LP, et al. (2014) Lower adiponectin is associated with subclinical cardiovascular disease among HIVinfected men. AIDS 28: 901-909.

11. Morimoto HK, Simão AN, de Almeida ER, Ueda LT, Oliveira SR, et al. (2014) Role of metabolic syndrome and antiretroviral therapy in adiponectin levels and oxidative stress in HIV-1 infected patients. Nutrition 30: 1324-1330.

12. Kumada M, Kihara S, Sumitsuji S, Kawamoto T, Matsumoto S, et al. (2003) Association of hypoadiponectinemia with coronary artery disease in men. Arterioscler Thromb Vasc Biol 23: 85-89.

13. National Cholesterol Education Program (NCEP) (2002) Third Report of the National Cholesterol Education Program (NCEP) Expert Panel on Detection, Evaluation, and Treatment of High Blood Cholesterol in Adults (Adult Treatment Panel III) final report. Circulation 106: 3143-3421.

14. Cui J, Panse S, Falkner B (2011) The role of adiponectin in metabolic and vascular disease: A review. Clin Nephrol 75: 26-33.

15. Vasseur F, Leprêtre F, Lacquemant C, Froguel P (2003) The genetics of adiponectin. Curr Diab Rep 3: 151-158.

16. Nedvídková J, Smitka K, Kopský V, Hainer V (2005) Adiponectin, an adipocytederived protein. Physiol Res 54: 133-140.

17. Yamauchi T, Kamon J, Waki H, Terauchi Y, Kubota N, et al. (2001) The fatderived hormone adiponectin reverses insulin resistance associated with both lipoatrophy and obesity. Nat Med 7: 941-946.

18. Hotta K, Funahashi T, Arita Y, Takahashi M, Matsuda M, et al. (2000) Plasma concentrations of a novel, adipose-specific protein, adiponectin, in type 2 diabetic patients. Arterioscler Thromb Vasc Biol 20: 1595-1599.

19. Hotta K, Funahashi T, Bodkin NL, Ortmeyer HK, Arita Y, et al. (2001) Circulating concentrations of the adipocyte protein adiponectin are decreased in paralle with reduced insulin sensitivity during the progression to type 2 diabetes in rhesus monkeys. Diabetes 50: 1126-1133.

20. Weyer C, Funahashi T, Tanaka S, Hotta K, Matsuzawa Y, et al. (2001) Hypoadiponectinemia in obesity and type 2 diabetes: Close association with insulin resistance and hyperinsulinemia. J Clin Endocrinol Metab 86: 19301935.

21. Laughlin GA, Barrett-Connor E, May S, Langenberg C (2007) Association of adiponectin with coronary heart disease and mortality: The Rancho Bernardo study. Am J Epidemiol 165: 164-174.

22. Okamoto $Y$ (2011) Adiponectin provides cardiovascular protection in metabolic syndrome. Cardiol Res Pract 2011: 313179.

23. Norton L, Brodine SK, Medina S, Lemus H, Ricchiuti V, et al. (2013) Adiponectin Levels and Coronary Artery Disease among HIV-Infected Men. J AIDS Clin Res 4: 208.

24. Lagathu C, Eustace B, Prot M, Frantz D, Gu Y, et al. (2007) Some HIV antiretrovirals increase oxidative stress and alter chemokine, cytokine or adiponectin production in human adipocytes and macrophages. Antivir Ther 12: $489-500$.

25. Jones SP, Qazi N, Morelese J, Lebrecht D, Sutinen J, et al. (2005) Assessment of adipokine expression and mitochondrial toxicity in HIV patients with lipoatrophy on stavudine- and zidovudine-containing regimens. J Acquir Immune Defic Syndr 40: 565-572. 
Citation: Kalyanasundaram AP, Jacob SM, Ramachandran H, Sivakumar MR (2015) Serum Adiponectin Levels and Their Association with Antiretroviral Therapy and Lipid Profile in HIV-Infected Individuals in South India. J AIDS Clin Res 6: 504. doi:10.4172/2155-6113.1000504

26. Bezante GP, Briatore L, Rollando D, Maggi D, Setti M, et al. (2009) Hypoadiponectinemia in lipodystrophic HIV individuals: A metabolic marker of subclinical cardiac damage. Nutr Metab Cardiovasc Dis 19: 277-282.

27. Palios J, Kadoglou NP, Lampropoulos S (2012) The pathophysiology of HIV-/ HAART-related metabolic syndrome leading to cardiovascular disorders: The emerging role of adipokines. Exp Diabetes Res 2012: 103063.

28. Lindegaard B, Keller P, Bruunsgaard H, Gerstoft J, Pedersen BK (2004) Low plasma level of adiponectin is associated with stavudine treatment and lipodystrophy in HIV-infected patients. Clin Exp Immunol 135: 273-279.

29. Kosmiski LA, Bacchetti P, Kotler DP, Heymsfield SB, Lewis CE, et al. (2008) Relationship of fat distribution with adipokines in human immunodeficiency virus infection. J Clin Endocrinol Metab 93: 216-224.

30. Tong Q, Sankalé JL, Hadigan CM, Tan G, Rosenberg ES, et al. (2003) Regulation of adiponectin in human immunodeficiency virus-infected patients: Relationship to body composition and metabolic indices. J Clin Endocrinol Metab 88: 1559-1564.

31. Luo L, Zhang L, Tao M, Qiu Z, Xie J, et al. (2009) Adiponectin and leptin levels in Chinese patients with HIV-related lipodystrophy: A 30-month prospective study. AIDS Res Hum Retroviruses 25: 1265-1272.

32. Schneider JG, von Eynatten M, Schiekofer S, Nawroth PP, Dugi KA (2005) Low plasma adiponectin levels are associated with increased hepatic lipase activity in vivo. Diabetes Care 28: 2181-2186.
33. Qiao L, Zou C, van der Westhuyzen DR, Shao J (2008) Adiponectin reduces plasma triglyceride by increasing VLDL triglyceride catabolism. Diabetes 57 : 1824-1833.

34. Matsubara M, Maruoka S, Katayose S (2002) Decreased plasma adiponectin concentrations in women with dyslipidemia. J Clin Endocrinol Metab 87: 27642769.

35. Marso SP, Mehta SK, Frutkin A, House JA, McCrary JR, et al. (2008) Low adiponectin levels are associated with atherogenic dyslipidemia and lipid-rich plaque in non-diabetic coronary arteries. Diabetes Care 31: 989-994.

36. Falasca K, Manigrasso MR, Racciatti D, Zingariello $P$, Dalessandro $M$, et al. (2006) Associations between Hypertriglyceridemia and Serum Ghrelin Adiponectin, and IL-18 Levels in HIV-infected Patients .Annals of Clinical \& Laboratory Science 36: 59-66.

37. Addy CL, Gavrila A, Tsiodras S, Brodovicz K, Karchmer AW, et al. (2003) Hypoadiponectinemia is associated with insulin resistance, hypertriglyceridemia and fat redistribution in human immunodeficiency virus-infected patients treated with highly active antiretroviral therapy. J Clin Endocrinol Metab 88: 627-636.

38. Samaras K, Gan SK, Peake PW, Carr A, Campbell LV (2009) Pro-inflammatory markers, insulin sensitivity, and cardio-metabolic risk factors in treated HIV infection. Obesity (Silver Spring) 17: 53-59. 